Zhang, J. \& Chen, K.(2020). Analysis of the Cores of the Improvement of Online Teaching System and Model Based on the Evaluation and Feedback on the Online Teaching Model and Teaching Platform Journal of Educational Technology Development and Exchange, 13(2), 95-105

\title{
Analysis of the Cores of the Improvement of Online Teaching System and Model Based on the Evaluation and Feedback on the Online Teaching Model and Teaching Platform
}

\author{
Jiangxue Zhang \\ Ocean University of China \\ Kaiquan Chen \\ Ocean University of China
}

\begin{abstract}
In recent years, MOOC, SPOC and other online teaching modes have attracted widespread attention. Online teaching platforms such as Tencent Classroom and MOOC of Chinese universities have emerged in an endless stream. During the 2020 outbreak of COVID-19, schools at all levels actively engaged in online teaching. The problems and challenges faced in the course of this teaching process will push the research hotspots of modern educational technology to construct the online teaching model that meets the needs of colleges and universities in the context of "Internet + Education". This study collected the evaluation and feedback of college students from different universities and different majors on online teaching mode and teaching platform, conducted a quantitative study of SPSS samples, and analyzed the influence of learners' and teachers' participation on online teaching effect. Results show that: there is a positive correlation between learners' attitude towards online teaching and the effect of online teaching, and between learners' participation and the effect of online teaching. There is also a positive correlation between teacher's participation and effect of online teaching. There is no clear correlation between learners' use of equipment and online teaching effectiveness. Through the interview, learners reported low self-evaluation in online learning, and there are some problems in the teaching process, such as lack of teaching experience, poor platform interaction ability, and low supervision ability of managers. This study argues that in the development of online teaching, learners' and platform users' sense of experience and teachers' participation should be further improved and perfected.
\end{abstract}

Keywords: online teaching, teaching mode, learning effect, teaching evaluation

Volume 13, No. 2, December, 2020 


\section{Introduction}

The development of Internet and media technology provides a solid network and technology foundation for online teaching, the development and application of various online teaching platforms and tools by the relevant educational institutions of high concern, online teaching model has become a popular but controversial topic in educational technology and related fields. According to the iMedia's Future Education Industry Research Center forecast, China's online education market and users will continue to expand at a much faster rate than traditional education. In recent years, through continuous development and improvement, the online teaching platform has made great progress in multimedia teaching, online resource sharing, individualized setting of teaching content, online mutual evaluation and learner analysis, etc. It is committed to realizing efficient teaching process, sharing high-quality resources and advancing with The Times teaching mode to make up for the deficiency of traditional teaching mode. In the special period of the outbreak, schools at all levels corresponding "closed not suspended", the largest online teaching, the teaching effect of instability reflects modern online teaching mode of short board and will face the challenge, for the causes of the formation of online teaching board, different scholars' arguments are given in terms of teaching process and teaching materials. Zheng Qinhua[1] believes that the degree of teacher's participation is the key to the improvement of the overall level of MOOC, but the current teacher's participation is obviously insufficient. Liu Yucheng [2] also confirmed the logical relationship among online teaching resources, interactive behavior and teaching effect. How to explain the relationship between teachers, learners and teaching effect, improve online teaching level and teaching effect, and make up for the lack of online teaching mode has become an urgent problem for educational scholars and relevant educational institutions. In view of these practical problems, this study analyzes the evaluation of various online teaching platforms and demonstrates the factors that affect the teaching effect of online teaching and learners, and the relationship between online teaching participants (learners, teachers and managers) and learners. And further analysis of a multi-choice, high interactive quality online teaching mode should have the conditions, and summed up the online teaching system and mode still need to improve and perfect the main points.

\section{Analysis of Existing Online Teaching Models at Home and Abroad}

Since the first year of online education in 2012, computer science, media technology, media psychology, artificial intelligence, higher education and other disciplines have paid high attention to the research of online teaching system and mode. Some scholars have studied the preferences of teachers and students, information literacy, online learning ability and motivation psychology in online teaching, and some scholars have studied blackboard and Tencent conference and other teaching platforms in specific subject courses, and do a more in-depth case study and teaching methods, analyze and construct the teaching mode in online teaching. In the term search of online teaching mode and teaching mode from 2015 to 2020 , through the retrieval results of quantitative visualization analysis of CNKI, we can clearly see that the relevant research literature is increasing year by year, and it is predicted that about 488 literatures will be published in the whole network in 2020. Under the situation of the epidemic situation in 2020, in addition to the previous years, MOOC, SPOC, B-Learning 
Analysis of the Cores of the Improvement of Online Teaching System and Model Based on the Evaluation and Feedback on the Online Teaching Model and Teaching Platform

and other topics, new research on the analysis of teaching in the epidemic situation was added.

Rosenberg, an American educator, sees E-Learning as a series of solutions that leverage network technology to enhance knowledge and job performance, he believes E-Learning as a model for going beyond typical traditional teaching. In China, E-Learning is divided into three types of understanding: Internet-based learning, electronic teaching, and the teaching process of combining digital content with network resources. All three emphasize digital technology, emphasizing the use of technology to assist and optimize the implementation process and methods of education, such as big data,5G, artificial intelligence, they begin to participate in the teaching system. In the past ten years of research and development, the integration of online teaching and traditional teaching in various colleges and universities is deepening, various online teaching platforms are springing up, and various teaching modes provide a new paradigm for online education. The beginning of MOOC is the beginning of learners' expansion of access to knowledge, and the sharing of high-quality educational resources has become the main aspect of constructing the teaching system. In the relevant studies of MOOC, it is found that it is weak in teaching management, and there will be a phenomenon of learning efficiency polarization among learners. In the teaching mode of MOOC, teachers are the necessary part of the interaction link, and the participation of teachers is the key part to improve the overall interaction level, but the feedback at this stage shows that the participation of teachers in the teaching process is far from insufficient. Phil Hill, an educational technical consulting expert and analyst based on MOOC teaching practices, classifies learners into five categories: absentees, bystanders, casual entrants, passive participants and active participants. Based on this analysis, it also explains the widespread problem of high exit and low participation rates for learners in online teaching, and demonstrates that online teaching requires more effective interventions.

The large-scale nature of MOOC mode makes it difficult to realize realtime communication between teachers and students, and there are great difficulties in both intervention and feedback. Therefore, interactivity has become the main direction of research and teaching system and mode. On the basis of MOOC model, Armando fox, a professor at the University of California, Berkeley, proposed a new online teaching mode SPOC mode in the post MOOC stage, which is a hybrid teaching mode of offline learning and online answering. In this mode, SPOC is still a tool to provide course resources. Student-centered learning leads to weak monitoring of learners' learning process by teachers and managers, and learners' selfdiscipline and autonomous learning ability become significant variables in teaching efficiency, in order to promote further networking and intelligent development of teaching, online teaching into the 4.0 era, the teaching mode of "Internet +" classroom teaching is the $\mathrm{O} 2 \mathrm{O}$ mode of combining online learning with traditional teaching. The one-way teaching into a multi-directional interactive form, a single teaching tool to multi-dimensional teaching space and interactive teaching community to expand, enhance the interaction between teachers and students or students and students. On this theoretical basis, the Learning Management System (LMS)has been developed to focus on the teaching and learning process, emphasizing learning management and interactive functions such as WebCT and the platform named Blackboard. In addition, there is also a streaming mode in recent days 
also attracted much attention and it is worth mentioning, although this model is only a teaching method model, not likes MOOC and SPOC at the same time with teaching concepts and teaching methods, but to a certain extent, it reveals the online education model short board, based on the reality, see the influence of the traditional teaching mode in online teaching deep-rooted, it is difficult to achieve the desired effect. For example, the common problem at this stage is that in most of the live classes, the traditional education model centered on teachers and textbooks continues, and the teaching atmosphere is not as strong as offline teaching.

From the above research, it can be seen that under the development of online teaching mode, different problems still exist in the current teaching mode, high dropout rate and low participation rate confirm the importance of intervention and teacher's participation in the teaching process. In past studies, specific courses in higher education have been presented as research examples (such as "Advanced Mathematics" SPOC course development and "Objectoriented programming" course design), they introduced the formation, characteristics and influence of online teaching under one of the online teaching modes, but there is very little analysis that combines the current variety of online learning models. However, through literature comparison, it is found that the shortcomings of teaching mode and teaching platform in recent years are highly overlapping. The summary is expected to form a more comprehensive and critical evaluation of online teaching mode, and is also conducive to the construction of online teaching mode and the design and planning of teaching platform in the future. Therefore, through the quantitative research method of SPSS sample, this paper analyzes the evaluation feedback of various online teaching modes and platforms, and summarizes the specific problems faced by the emerging teaching model and the specific aspects of improvement.

\section{Research design and methods}

Quantitative research methods (quantitative research) are generally designed to produce statistical results for the overall population of a particular subject. Through the analysis of the data of the samples taken by the research object, summarize the law of variation of the samples to confirm the validity of the hypothesis and the theory of testing. The sample collection tool is Wenjuanxing, which is a professional online questionnaire survey, evaluation and voting platform, supporting custom design of questionnaires and online large-scale distribution and recycling of questionnaires. The data analysis tool used to analyze the samples is SPSS (Statistical Product and Service Solutions), a Statistical software developed by IBM, which can help statisticians with Statistical analysis operations, data mining, predictive analysis and decision support tasks.

\section{1. quesstionnaire design and collection}

The study was limited to college grades, so the questionnaire was given to college students who were using media devices for online learning. This study involved 50 undergraduate students from different universities and different grades, including $53 \%$ male students and $47 \%$ female students, $6 \%, 84 \%$ and $10 \%$ freshmen, sophomores and juniors. One male sophomore and one female sophomore were randomly selected for interviews.

The questionnaire uses the Wenjuanxing website to set up five sections of the question, respectively involving personal information, 
Analysis of the Cores of the Improvement of Online Teaching System and Model Based on the Evaluation and Feedback on the Online Teaching Model and Teaching Platform

the use of online teaching platform, online teaching activities, evaluation of online teaching and self-evaluation, apart from the personal information section, two questions were set for each section, and there were eight questions in total. The use of the online teaching platform is mainly to understand the teaching platform used by the teaching, the scope of use and the use experience of learners' equipment, so as to demonstrate whether the use experience of learners' equipment has an impact on the effect of online teaching. The situation of online teaching activities includes the interactive situation in the teaching process, which proves that there are still interactive shortcomings in online teaching at the present stage. The evaluation of online teaching including the learner's attitude towards teacher's participation, explore capacity, and evaluation of the platform in terms of data sharing, interaction and supervision, and the attitude of learners towards online teaching, to demonstrate whether the attitude of learners has an impact on the teaching effect. Selfevaluation explores learners' attitudes toward online teaching by asking learners about their learning satisfaction and predicting the frequency of future online learning. Questionnaires are sent and collected online by means of TWO-DIMENSIONAL code pictures.

After the questionnaires are collected, the validity of the answers in the Wenjuanxing is first screened to remove the invalid or inefficient answers, and then the institutions are screened to prevent the excessive sample proportion of a certain school. After screening, a total of 40 valid samples were obtained, and the data were imported into SPSS for analysis. The content of the interview is the reasons and explanations for each score of the questionnaire.

\section{2. relevance test}

Correlation refers to the degree to which two variables are associated. Correlation analysis refers to the analysis of two or more related variable elements to measure the closeness of the correlation between two or more variable factors.

SPSS is used for sample data analysis due to the large amount of computation in this study sample. In SPSS, the P-value is for the original hypothesis $\mathrm{H} 0$ : assume that the two variables without linear correlation. The significance level of the general hypothesis test(sig)is 0.05 , and if the $\mathrm{P}$ value is less than 0.05 , the rejection of the original hypothesis $\mathrm{H} 0$ indicates a linear correlation between the two variables.

\section{Data Analysis and Discussion}

After the questionnaire survey, it is found that most learners think online teaching is inefficient, Table 1 shows the verification results of relevant guesses, and Q1 Q4 are the factors that are considered to have an impact on teaching efficiency after screening the questionnaire results. It is possible to verify whether each factor can explain the low efficiency of online teaching in the feedback from the two aspects of the existence of correlation and correlation coefficient:

In the data collection, some common conditions were found: Learners have a large score gap when evaluating their selflearning efficiency, and a large polarization when expressing their attitudes toward online teaching. When observing the samples, it is found that learners who give high marks to the online teaching mode tend to think that their learning efficiency is higher in online learning than in offline learning. Therefore, it is speculated that: There may be a relationship between learner attitudes and teaching efficiency (Q1). Through the test, the Relation coefficient of Q1 in Table 
1 is 0.440 , which proves that there is a correlation and a positive correlation between learners' preference for online learning and their evaluation of online teaching efficiency, there are situations where attitude influences assessment, or learning efficiency influences attitude, or both.

In this study, the samples are taken from college students, who have few operational problems in the application of computer media and other technologies, and there are no samples in the overall samples that are unable to operate electronic equipment. There is speculation as to whether the current inefficiency of online teaching is due to the lack of online teaching experience (Q4). But no correlation was found after testing the sample data. It proves that college learners' evaluation of teaching efficiency is not influenced by their own online learning experience.

Q2 proves that there is a positive correlation between teacher's supervision and online teaching efficiency, which verifies Phil Hill's theory that teaching needs intervention. Q3 proves that there is a positive correlation between learner engagement and online teaching efficiency, and verifies that improving learner engagement is one of the keys to improving online teaching level. Q1 Q4 were also proved in subsequent interviews, learners believe that teachers' supervision may be more important in the above four aspects affecting the teaching effect, compared with traditional teaching mode, online teaching has more freedom for learners, and it is difficult for teachers to take compulsory measures for learners to ensure the course schedule and homework completion, both of interviewees said that they had been absent-mindedness and homework plagiarism during the study period, and they believed that such behavior might be the normal behavior of learners under the online teaching mode.

Table 1. The factors that are considered to have an impact on teaching efficiency.

\begin{tabular}{llcc}
\hline Question & \multicolumn{1}{c}{ Concrete problems } & Correlation & $\begin{array}{c}\text { Relation } \\
\text { coefficient }\end{array}$ \\
\hline Q1 & $\begin{array}{l}\text { Evaluation of online teaching efficiency and learners' } \\
\text { attitude }\end{array}$ & related & 0.440 \\
Q2 & $\begin{array}{l}\text { Efficiency of online teaching and learners' experience in } \\
\text { using equipment }\end{array}$ & non-related & \\
Q3 & $\begin{array}{l}\text { Evaluation of online teaching efficiency and teacher's } \\
\text { supervision } \\
\text { Evaluation of online teaching efficiency and learner's } \\
\text { participation }\end{array}$ & related & 0.670 \\
& related & 0.720 \\
\hline
\end{tabular}

We believe that the quality of online teaching platform is also an important aspect to ensure the teaching level, the questionnaire evaluated learners from four aspects: interaction ability, supervision ability, data sharing ability and practicality (see Table 2 ). It can be seen that most learners believe that resources in online teaching are relatively sufficient, but interaction ability is slightly deficient, while supervision ability still has many defects. Table 3 shows learners' ratings of the top three teaching platforms in terms of usage, it can be seen that the scores of the three platforms are low (the full mark of 
Analysis of the Cores of the Improvement of Online Teaching System and Model Based on the Evaluation and Feedback on the Online Teaching Model and Teaching Platform

the rating scale is 5). Learners give some reasons for the low scores: Moocs in Chinese universities have no interaction and are largely unregulated. The QQ group will drop the line if there are too many people in the class, the voice and picture will not be synchronized, the note name can only be changed on the mobile phone, and can't achieve video discussion. Tencent Conference's message boxes are easy to ignore and difficult to communicate in real time. In the further investigation of interaction ability, it is found that the interactions between the students and teachers, students and students, even the teachers and teachers, more than half of the learners think that the interaction in the current online teaching mode is too troublesome. Learners believe that complex interactive operations aggravate the pressure in the interaction, which is the reason for the low participation of online learning learners. We believe that the interactive ability of the teaching platform can not only affect learners' participation, but also affect teachers' participation.

Table 2. The competency assessment of teaching platforms

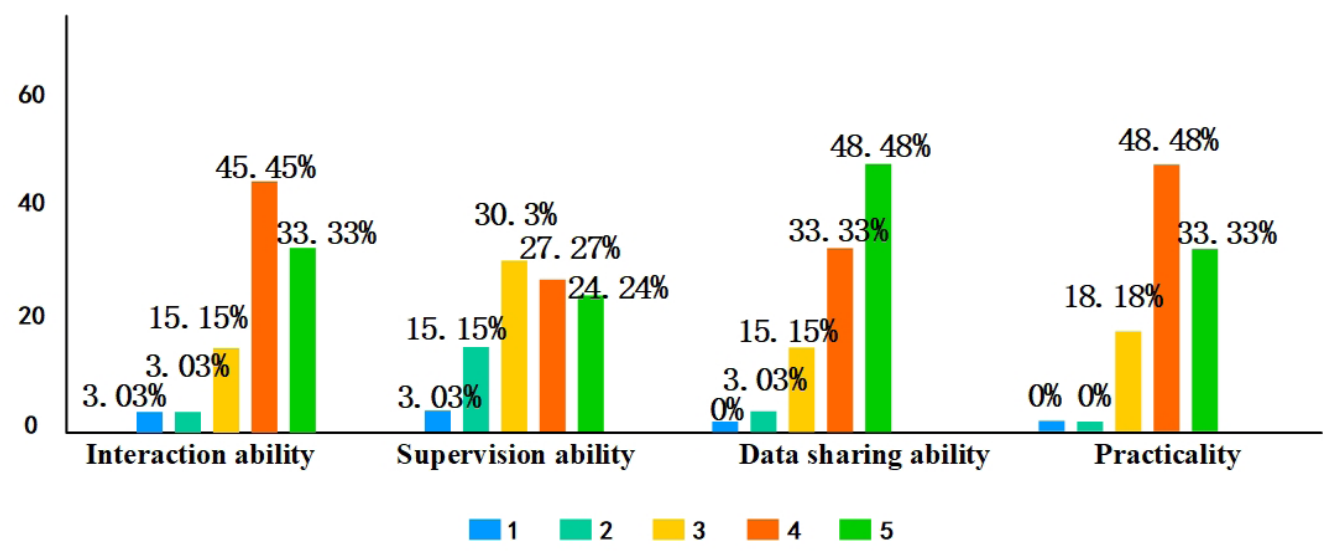

Table 3. The average score of teaching platforms.

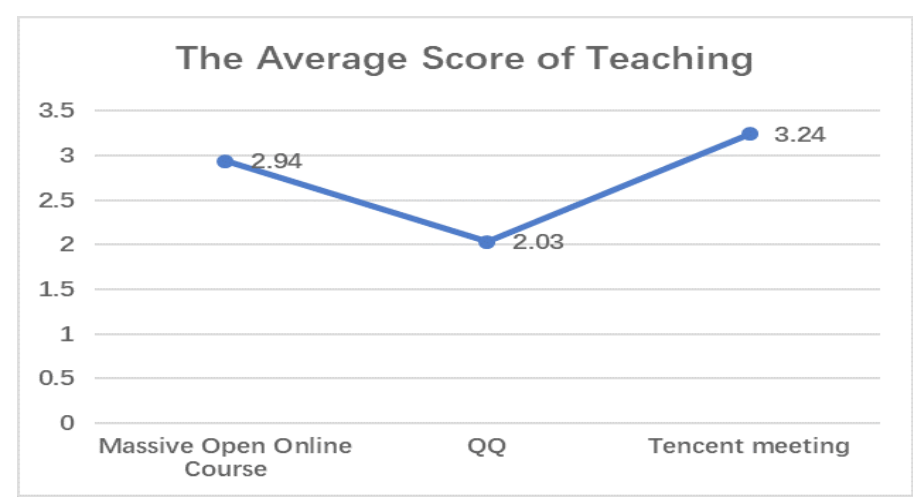

Volume 13, No. 2, December, 2020 
In order to verify the issue of teacher participation in online teaching, this study conducted an interview with teachers about their interaction. It is found that teachers show different attitudes towards participation in the same course on different teaching platforms or different courses on the same platform, this attitude will reflect the high degree of involvement of the educator due to the platform device support and the improvement of the fitness of the course in online teaching. However, according to the scores of learners' participations in the teaching process in Table 4, there is still a lack of participation in online teaching, $60.61 \%$ of learners believe that compared with offline teaching, teacher's participation in online teaching is lower. Limited by media technology and other restrictions, online communication is far less effective than face-to-face communication.

\section{Table 4. Teachers' participation.}

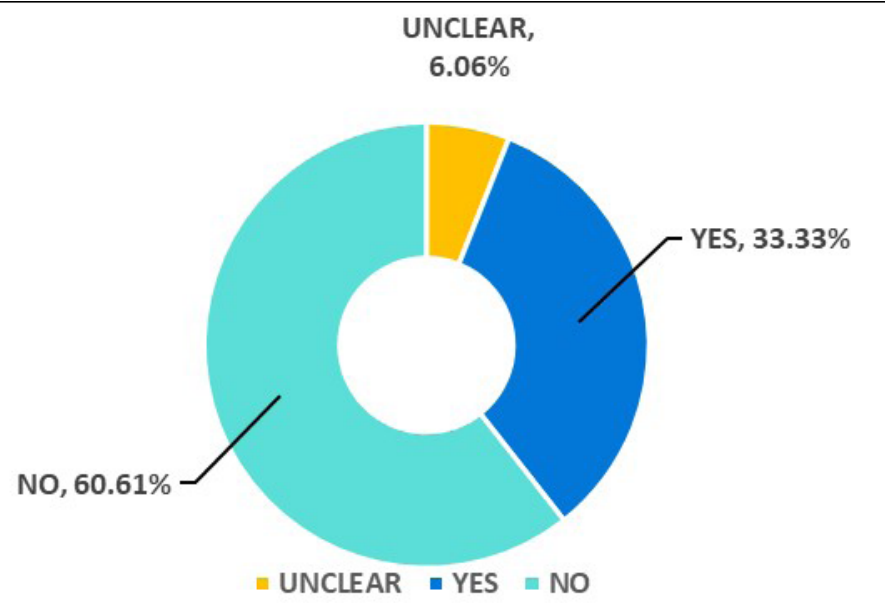

Based on the above analysis, it can be seen that there is a big difference between the online teaching mode and the traditional teaching mode in terms of teaching process and learning methods, and it still takes some time for teachers and students to transform and adapt to the new mode. Through the summary of the questionnaire and interview results, it is found that the questions can be divided into three directions:

\subsection{Learner's Feelings of Experience}

These include the difficulty level of platform operation, evaluation mode, the type of course and the feelings of using platform. The difficulty level of platform operation is proposed for the teachers, so the difficult operation should be reduced or the operation training should be carried out, so that the older teachers can easily operate the platform. Many platforms with multifarious new functions can enhance the attraction for gimmicks, but the operation is tedious and practical. Compared with the offline teaching, the assessment methods are more troublesome, physical education and practice classes are difficult to be assessed online. The blind pursuit of online teaching neglects the adaptability of curriculum and teaching transmission mode, at present, some class which need teacher's instruction or need students to 
Analysis of the Cores of the Improvement of Online Teaching System and Model Based on the Evaluation and Feedback on the Online Teaching Model and Teaching Platform

operate can't fully adapt to the development of online teaching. This undoubtedly increases the difficulty of course learning and learners' pressure. The learning burden and unsatisfactory results easily turn into the resistance attitude towards online teaching, thus affecting the teaching effect. And we find that data between different platforms cannot be intercommunicated at this stage, which will be relatively troublesome for users who use multiple platforms for teaching or learning. Therefore, in terms of the above problems, the realization of data circulation among multiple media and platforms is a solution to enhance the feelings of using the platform and enhance the convenience of online learning. The data exchange not only exists among various teaching platforms and media, but also some life activity platforms can share data. For example, the sports platform can be used for the teaching of physical education, and the library system can support the progress tracking of reading tasks in the teaching platform. The realization of multiplatform synchronized data is conducive to cross-platform learning and teaching for learners and educators, keeping their positive attitude towards online teaching.

\subsection{Participation of teachers in the interaction}

Previous studies have focused on the problem of improving interaction between teachers and students, students and students, this study refers to the problem of interaction between teachers and teachers, because we think interaction is not only between teachers and learners, more need sing-through between teachers, and that teachers need to learn new teaching methods in contrast and reflection to adapt to different teaching situations, rather than to be self-contained, Good communication can make the teacher realize the short board in the teaching process and correct and progress it. But it's hard to do that in online teaching. During this teaching period, some of the teachers showed bad atmosphere to prove that the construction of a good teaching environment also needs to restrain the behavior of the teachers. The online teaching platform should give attention to the teacher, set up the learner's evaluation and give the teacher classroom monitoring, form the feedback report to the teacher, through the supervision and supervision of teaching style, teaching method, teaching progress, teaching content and teacher's initiative, create a good teaching environment, resist bad atmosphere, and improve the quality of online teaching.

\subsection{Classroom Supervision Issues}

Under the online teaching mode, emphasizing that students' self-learning, poor supervision, the existing regulatory methods are mostly check-in or teachers forced to turn on the camera, the former is weak in supervision, basically teachers difficult to manage the classroom, the latter part of the learners have antipathy to open the camera and microphone psychological phenomenon, and think that camera surveillance and computer mobile phone interface monitoring behavior will invade privacy, resulting the phenomenon of conflict with online teaching. It is still difficult to find an acceptable range between the degree of psychological conflict and the degree of supervision. In order to achieve strong intervention, teachers still need to pay more attention to learners in class.

\section{Summary}

By collecting learners' and teachsers' comments on online teaching and their feedback on the teaching platforms, this study aims to explore the shortcomings of the current online teaching model, and 
gets the following conclusions: There is a certain correlation between learners' attitude and online teaching effect, while there is no clear correlation between learners' experience in using equipment and platform. The supervision of teachers and learners' participation in the teaching process have a certain correlation with the effect of online teaching, and finds that the teaching platform lacks the function of communication between teachers and the supervision of teachers. This study only focuses on the deficiencies of online teaching mode and platform, which cannot represent the overall evaluation of online teaching and each teaching platform, and lacks evaluation samples of platform managers, which has certain limitations. In the future, on the basis of knowing the deficiencies at the present stage, we will improve the platform functions, improve the abilities of teachers and find better solutions to the problems of curriculum supervision under the development of science and technology.

\section{Contact the Author}

\section{Jiangxue Zhang}

Department of Education

Ocean University of China

Qingdao, China

zjxzq17863964663@163.com

\section{Kaiquan Chen*}

Department of Education

Ocean University of China

Qingdao, China

chenkqsd@163.com 
Analysis of the Cores of the Improvement of Online Teaching System and Model Based on the Evaluation and Feedback on the Online Teaching Model and Teaching Platform

\section{References}

Zhen Q H, Li Q J, \& Chen L. (2015). Research on MOOCS Teaching Mode in China $[\mathrm{J}]$. Education Research, v.21;No.118(06), 71-79.

Liu Y C, Wang C S, \& Yang J. (2019). Structural Analysis and Empirical Research of "IDCNN +" Teaching Mode of" Rain Classroom" [J]. Journal of Distance Education, 37(01), 96-105.

Chen X J, \& Chen H P. (2015). Tencent Classroom Online Teaching Model Research [J]. Software Guide(08), 221224.

Guo H, Liu H X, \& Tang L Y. (2020). Research and Practice of Blended Teaching of Advanced Mathematics Based on Online Teaching Platform [J]. Course Education Research(05), 131-132.

Wang Q R. (2010). Thinking on the Teaching Mode of BlackBoard Online Teaching Management Platform [J]. Journal of Jiaying University(10), 77-81.

Ormond S, \& translated by Xiao J H. (2015). Face-to-Face Teaching of Distance Education -- Literature Review and Case Review [J]. Distance Education in China(9).

Hua L N. (2019). On the Optimization of Course Teaching Design Based on Online Teaching Platform $[\mathrm{J}]$. Asia-Pacific Education.

Yuan H, \& Liu Y. (2020). Research on the Blended Teaching Mode of University Classroom Based on Mobile Learning -- Taking the Application of Super Star Learning Pass As an Example [J]. Teaching of Forestry Region, No.276(03), 21-23.

Xiu T (2016). Research on the Teaching Method Design of MOOC [J]. The Modern Education Journal.
Yang H J, Zhang H P, \& Cheng P. (2020). Analysis of Online Teaching in Colleges and Universities During COVID-19 Epidemic [J]. China Journal of Multimedia \& Network Teaching(04), 199-201.

Chen G, Xie X L, \& Liu H Y. (2020). Construction of Differentiated Blending Learning Mode Based on SPOC in Colleges and Universities [J]. University Education, 000(004), 10-12,28.

Sun. Z H. (0). Online Teaching 4.0:" Internet +" Classroom Teaching $[\mathrm{J}]$. The Chinese Journal of ICT in Education(14), 17-20.

Bao Z Z. (0). Design and Implementation of Online Teaching Platform [J]. (Doctoral dissertation).

Zhang X. (2013). Inspiration and Reconsideration of MOOC Online Teaching Mode -- From the Perspective of the Practice of Jiangsu Open University [J]. Journal of Jiangsu Open University(5), 5-10.

Wei B S.(2018). Analysis on the Problems and Countermeasures of Live Teaching in Open Education[J]. Journal of Jilin TV \& Radio University(08),98-99+112. doi:.

Zhou J, An T, Han X Q. On Construction of Live Teaching Model and Case Analysis in Mobile Internet Era[J]. Vocational and Technical Education, 2018,39(29):33-38. 